\title{
A PRODUÇÃO DA PSICOLOGIA SOCIAL SOBRE TEMAS POLÍTICOS A PARTIR DE ASPECTOS HISTÓRICOS
}

\author{
LA PRODUCCIÓN DE LA PSICOLOGÍA SOCIAL SOBRE \\ TEMAS POLÍTICOS A PARTIR DE ASPECTOS HISTÓRICOS \\ THE PRODUCTION OF SOCIAL PSTCHOLOGY ON \\ POLITICAL TOPICS FROM HISTORICAL ASPECTS
}

\author{
Frederico Alves Costa ${ }^{1}$
}

${ }^{1}$ Universidade Federal de Alagoas, Maceió/AL, Brasil

\begin{abstract}
RESUMO: O objetivo do texto é discutir produções científicas sobre temas políticos publicadas no campo da psicologia social brasileira após o fim do regime civil-militar no Brasil, a partir do contexto histórico desta produção. Os artigos foram publicados por pesquisadores/as vinculados/as a programas de pós-graduação brasileiros em Psicologia Social ou em Psicologia e que identificavam a psicologia social como área de atuação no currículo Lattes. Foi possível articular os debates propostos nestes artigos a aspectos relevantes do contexto de produção como a "crise da psicologia social", a democratização da política de saúde no Brasil, a política científica desenvolvida nos governos do PSDB e do PT. Ressalta-se o crescimento do debate sobre políticas públicas na produção selecionada e a importância de se problematizar a inibição da produção científica não apenas em regimes totalitários, mas também em regimes democráticos.
\end{abstract}

PALAVRAS-CHAVE: Psicologia social; Temas políticos; Política pública; PT; PSDB.

RESUMEN: El objetivo del texto es discutir producciones científicas sobre temas políticos publicadas en el campo de la psicología social brasileña tras el fin del régimen civil-militar en Brasil a partir del contexto histórico de esta producción. Los artículos fueron publicados por investigadores/as vinculados/as a programas de postgrado brasileños en psicología social o en psicología y que identificaban la psicología social como área de actuación en el currículo Lattes. Se pudo articular los debates propuestos en estos artículos a aspectos relevantes del contexto de producción como la “crisis de la psicología social”, la democratización de la política de salud en Brasil, la política científica desarrollada en los gobiernos del PSDB y del PT. Se resalta el crecimiento del debate sobre políticas públicas en la producción seleccionada y la importancia de problematizarse la inhibición de la producción científica no sólo en regímenes totalitarios, sino también en regímenes democráticos.

PALABRAS CLAVE: Psicología social; Temas políticos; Política pública; PT; PSDB.

ABSTRACT: The purpose of the article is to discuss scientific productions on political topics published in the field of Brazilian social psychology after the end of the civil-military dictatorship in Brazil, from the historical context of this production. The articles were published by researchers associated to Brazilian Social Psychology or Psychology post-graduate programs who identified social psychology as their field of study in the Lattes curriculum. It was possible to articulate the debates proposed in these articles to relevant aspects of the production context such as the "social psychology's crisis", the democratization of health policies in Brazil, the scientific policies developed during the governments of the PSDB and PT parties. The growth of the debate on public policies in the selected production is highlighted, as well as the importance of problematizing the inhibition of scientific production not only in totalitarian regimes, but also in democratic regimes.

KEYWORDS: Social psychology; Political topics; public policy; PT; PSDB. 


\section{Introdução}

A reflexão sobre a produção científica de um campo de conhecimento é uma das possibilidades de abordar sua história, sendo a história da ciência entendida neste texto não como um desenvolvimento linear rumo a um conhecimento verdadeiro, mas como marcada por seu contexto de produção. Compreensão possível, ao se conceber a realidade como simbólica, e, assim, construída através da mediação discursiva em um contexto histórico específico (Laclau \& Mouffe, 1985).

No caso da investigação de temas políticos, a consideração do contexto de produção torna-se ainda mais relevante, pois pode inibir ou mesmo impossibilitar a abordagem de determinados temas, mas também ampliar a possibilidades de reflexões críticas sobre os processos de reprodução e transformação da sociedade.

A ditadura civil-militar brasileira, construída após o golpe de 1964, entendida, segundo Motta (2014), como um regime de modernização conservadora e autoritária, por um lado, fomentou investimentos em pesquisa e na pós-graduação no país. Por outro lado, entretanto, este fomento foi conduzido sob censura, perseguição, demissão, tortura, morte a pesquisadores/as considerados ideologicamente suspeitos, e instituições universitárias foram invadidas já nos primeiros anos do regime civil-militar (Guedes, 2007; Motta, 2014; Moreira, 2014).

Nos anos de democracia recente, podemos destacar o fomento à pesquisa e à pós-graduação no período dos governos Lula (2003-2010), contexto no qual a política científica foi construída pelo governo federal em consonância com a reflexão sobre processos de democratização da sociedade brasileira (Pavan Serafim \& Peixoto Dagnino, 2011).

O objetivo deste artigo é discutir a produção científica sobre temas políticos no campo da Psicologia Social brasileira após o fim do governo militar a partir de alguns aspectos históricos referentes ao contexto desta produção científica. No que diz respeito ao período em que a presidência da república foi assumida por dois importantes partidos políticos que atuaram no reestabelecimento da democracia no Brasil - o Partido da Social Democracia Brasileira (PSDB) e o Partido dos Trabalhadores (PT) -, focalizaremos produções sobre políticas públicas.

\section{Metodologia}

As produções científicas discutidas neste artigo foram selecionadas a partir de um mapeamento de pesquisadores/as vinculados a programas de pós-graduação (PPG) brasileiros em Psicologia Social e a PPG em Psicologia, que tivessem área de concentração em Psicologia Social ou linhas de pesquisas em psicologia social e/ou que apresentassem relação direta com temas políticos. Além desta vinculação, outros dois critérios para a seleção dos/as pesquisadores/as eram a identificação da Psicologia Social como área de atuação no currículo Lattes e a publicação de artigos sobre temas políticos ${ }^{1}$.

\footnotetext{
1 Os artigos foram selecionados através da presença de termos-chaves no título, conforme Costa (2014), e do objetivo apresentado no resumo.
} 
A partir deste mapeamento, selecionamos 169 pesquisadores/as, de 37 PPG diferentes, e coletamos 338 artigos $^{2}$. Após a leitura dos resumos dos artigos, focalizando o objetivo de cada um deles, e os categorizamos em seis categorias temáticas.

Tabela 1 - Categorias temáticas por quantidade de artigos

\begin{tabular}{|c|c|}
\hline Categoria temática & Artigos \\
\hline $\begin{array}{c}\text { Concepções sobre temas políticos e construção de práticas cotidianas: } \\
\text { análise de concepções dos indivíduos sobre temas políticos e suas } \\
\text { implicações em práticas cotidianas ou de práticas cotidianas relativas } \\
\text { ao enfrentamento/reprodução de relações de dominação. }\end{array}$ & 164 \\
\hline $\begin{array}{c}\text { Modelos teóricos e dimensão política: análise de modelos teóricos refe- } \\
\text { rentes a relações de dominação ou sobre a relação entre ciência e política. }\end{array}$ & 73 \\
\hline $\begin{array}{c}\text { Política pública: análise de políticas públicas quanto } \\
\text { à avaliação, construção e/ou atuação profissional. }\end{array}$ & 58 \\
\hline $\begin{array}{c}\text { Ação coletiva: análise da dinâmica de movimentos sociais } \\
\text { ou de outras formas de comportamento coletivo. }\end{array}$ & 25 \\
\hline $\begin{array}{c}\text { Intervenções políticas: análise de intervenções, distintas das políticas } \\
\text { públicas, que visam visibilizar e enfrentar relações de dominação. }\end{array}$ & 07 \\
\hline $\begin{array}{c}\text { Estado: análise da organização do Estado, focalizando as } \\
\text { estruturas institucionais e a atuação de partidos políticos. }\end{array}$ & 11 \\
\hline
\end{tabular}

Ao considerarmos a distribuição dos artigos por períodos temporais, tomando como critério o regime civil-militar e os governos democráticos recentes, temos a seguinte distribuição: período da ditadura militar, quatro artigos; primeira década após o fim do último governo militar (1985-1994), 11 artigos; governos do PSDB (1995-2002), 30 artigos; governos do PT (2003-2014), 293 artigos.

Em razão do grande número de artigos entre os anos 1995-2014, debateremos em relação a este perído apenas aqueles categorizados em "políticas públicas", centrando-nos em artigos referentes ao tema "Políticas públicas dirigidas à pobreza e à vulnerabilidade social” no caso do período dos governos do PT.

A escolha pela categoria temática Políticas Públicas decorre de ser a com maior crescimento proporcional no número de publicações no período entre 1995 e 2014 (ver Tabela 2), o que sugere uma ampliação da reflexão sobre direitos sociais através da intervenção do Estado. Em termos acadêmicos, a produção sobre políticas públicas é importante devido a relevância da crítica sobre o papel destas políticas no processo de democratização social. Em termos profissionais, cabe-nos ressaltar que as políticas públicas têm sido, desde a redemocratização do país, um dos principais espaços de inserção profissional de psicólogos no Brasil.

Já a escolha por abordar apenas os artigos referentes ao tema "Políticas Públicas dirigidas à pobreza e à vulnerabilidade social”, no período dos governos do PT, decorre de ser um dos temas com maior número de artigos no interior da categoria Políticas

2 Estabelecemos cinco períodos temporais (1966-1975; 1976-1985; 1986-1995; 1996-2005; 2006-2014), selecionando para cada pesquisador, no máximo, dois artigos por período. Devido ao objetivo proposto neste texto, fizemos uma pequena alteração na delimitação dos períodos temporais. 
Públicas neste contexto (ver Tabela 3), apresentando a especificidade de todos terem sido publicados nestes governos. Assim, além do aspecto quantitativo, consideramos também a preocupação dos governos do PT em articular o tema da exclusão/inclusão social com a política científica (Pavan Serafim \& Peixoto Dagnino, 2011).

\section{A primeira década após o último governo militar (1985-1994): consolidação da pós-graduação no país, redemocratização, mudanças teórico-metodológicas}

Neste período temporal, tivemos 11 artigos selecionados, número menor que o das décadas posteriores. Um aspecto a se considerar quanto a esta diferença numérica é o período de formação dos docentes. Dos 161 docentes que informavam na Plataforma Lattes a realização de mestrado, 82\% defenderam-no a partir de 1986. Dos 169 que realizaram doutorado, 80,5\% terminaram-o a partir de 1996.

Um segundo elemento é que a pós-graduação no Brasil é um empreendimento relativamente recente (Tourinho \& Bastos, 2010). A CAPES e o CNPq foram criados apenas em 1951, e uma concepção definitiva do sistema de pós-graduação no país só passou a existir a partir de 1965, início da ditadura civil-militar no país, com o parecer Newton Sucupira, do Conselho Federal de Educação, que ressaltava a pós-graduação stricto sensu como um fim essencial à universidade (Tourinho \& Bastos, 2010). Segundo Bomeny (2014), a expansão e a consolidação da pós-graduação foi viabilizada apenas na Reforma Universitária de 1968, que estabeleceu a indissociação entre ensino e pesquisa, institucionalizando a pesquisa como uma função da universidade.

Apesar do fomento à pesquisa e à pós-graduação nos anos ditatoriais, a pós-graduação no Brasil tem se estruturado mais fortemente nas últimas duas décadas, sendo possível observar uma tendência crescente na criação de programas de mestrado e doutorado, bem como de bolsas de pesquisa. De acordo com Brasil/MEC/CAPES (2010), saltamos de menos de 250 cursos de doutorado, e aproximadamente 500 cursos de mestrado, em 1976, para aproximadamente 500 cursos de doutorado e 1000 cursos de mestrado, em 199,0. De aproximadamente 600 cursos de doutorado e 1200 de mestrado, em 1995 para aproximadamente 1000 cursos de doutorado e 1800 cursos de mestrado em 2003, e mais de 1500 cursos de doutorado e de 2500 cursos de mestrado, em 2010.

Os PPG em Psicologia também seguiram esta tendência de crescimento ${ }^{3}$. Segundo Tourinho e Bastos (2010), de 1996 para 2008, tivemos um aumento global de 150\% no número de PPG em Psicologia no país. Crescimento quantitativo que tem sido acompanhado de um avanço qualitativo, demonstrado, segundo os autores, por indicadores como: (a) produção mais expressiva dos docentes dos PPG em revistas bem avaliadas; (b) intercâmbios mais frequentes com pesquisadores do país e do exterior; (c) maior atuação na comunidade científica internacional (editoração em revistas, participação em eventos, etc.).

Junto a este avanço da política científica no Brasil nas últimas décadas, não podemos deixar de considerar também a cobrança por produtividade dos docentes nos últimos anos, diante do peso deste item na avaliação dos PPG. A crítica ao que se denominou de

3139 pesquisadores investigados realizaram formação em mestrado e/ou doutorado em Programas de Pós-graduação em Psicologia Social ou em Psicologia. 
"produtivismo" - que não se trata de não reconhecer a importância da produção científica pelos pesquisadores e a consideração desta na avaliação dos PPG, mas da insatisfação com o modo como esta produção é avaliada -, segundo Yamamoto, Tourinho, Bastos e Menandro (2012), não se restringe ao Brasil nem a uma área ou outra, mas é geral.

No que diz respeito ao conteúdo dos 11 artigos, estes se encontram distribuídos em três categorias temáticas. Quanto aos categorizados em "Ações coletivas", observa-se em Stralen (1989) o debate sobre a atuação de movimentos sociais no processo de democratização da política pública de saúde, no qual o autor aborda a luta pela equiparação da assistência médica urbana e rural. A política pública de saúde também foi abordada em outros dois artigos de Stralen (1983, 1984) mapeados na pesquisa.

Em relação a este debate, cabe-nos ressaltar a importância do movimento sanitarista no processo de redemocratização do país e de reconfiguração do sistema de saúde nos anos 1980. A criação do Sistema Único de Saúde (SUS), fruto das articulações políticas progressistas deste período, foi uma das primeiras e mais importantes conquistas da sociedade brasileira, no que se refere às políticas públicas, após o fim da ditadura civil-militar.

No outro artigo localizado na categoria "Ações coletivas", Sandoval (1989) aborda uma discussão importante no campo das ações coletivas nos anos 1980: a retomada da investigação sobre movimentos sociais pela Psicologia Social a partir de perspectivas psicossociológicas que buscassem romper com o hiato entre estrutura e agência e investigar a dinâmica interna dos movimentos sociais.

A ênfase na construção de perspectivas psicossociológicas no campo das ações coletivas possibilitou a emergência da teoria dos "novos movimentos sociais". Teoria que abrange abordagens heterogêneas, que focaliza a expansão do campo político para além do campo institucional e a crítica a um sujeito racional e unitário, construindo-se uma compreensão do sujeito como descentrado e não essencializado (Prado, 2001).

A preocupação com a superação do hiato entre agência e estrutura social também é observada em investigações sobre a relação entre valores dos indivíduos e comportamento político (categoria "Concepções sobre temas políticos e construção de práticas cotidianas”), focalizando-se os processos de participação política e de socialização política.

Debate que pode ser verificado nos artigos de Camino e Costa (1994) e Costa, Torres, Burity e Camino (1994), nos quais os autores, a partir de uma perspectiva psicossociológica, discutem uma temática imbricada com o retorno das eleições diretas no país após o fim da ditadura civil-militar: o comportamento eleitoral. O pressuposto que orientava a investigação dos autores, como se afirma na introdução de um dos artigos, é que "O bom funcionamento da democracia pressupõe uma participação política responsável dos cidadãos" (Camino \& Costa, 1994, p. 01).

A "crise da psicologia social brasileira” foi um aspecto histórico importante para esta reorientação psicossociológica na investigação de temas políticos no Brasil em razão do questionamento de pressupostos que fundamentavam a produção hegemônica da Psicologia Social até os anos 1970/80, como o individualismo, o adaptacionismo, a-historicismo (Lane \& Codo, 1987; Sandoval, 2002). Duas discussões caras a este contexto de constituição de uma psicologia social crítica no Brasil - o conceito de ideologia e a proposta metodológica da pesquisa ação-participante - estão presentes em dois dos artigos mapeados: Bosi (1992), categorizado em "Concepções sobre temas políticos e construção de práticas cotidianas", e Sawaia (1989), categorizado em "Modelos teóricos e dimensão política". 
A influência da "crise" nesta reorientação da Psicologia Social brasileira também se remete à preocupação com o debate sobre diferentes relações de dominação presentes no país, o que pode ser observado na discussão sobre classe popular, racismo e desigualdade de gênero presente em artigos categorizados em "Concepções sobre temas políticos e construção de práticas cotidianas" (Coutinho, 1990; Mello, 1994; Sandoval, 1991) e em "Modelos teóricos e dimensão política” (Mello, 1992; Ferreira, 1993).

\section{Governos FHC (PSDB) e governos Lula e Dilma (PT): discrepância no número de produções sobre temas políticos e o debate sobre políticas públicas}

No que diz respeito à distribuição da produção científica selecionada nestes períodos, como já apontamos, há uma grande diferença numérica entre o período dos governos FHC e dos governos PT. Nos dois primeiros anos do governo Lula, foram selecionados mais do que o dobro de artigos em relação a todo o período dos governos FHC: 62 artigos.

Esta diferença numérica pode ser observada em todas as categorias temáticas, sendo "Intervenção política" ( 4,5 vezes) a categoria com menor crescimento e "Política Pública" (18 vezes) a categoria com maior crescimento no período entre 1995 e 2014.

Tabela 2 - Quantidade de artigos publicados entre 1995 e 2014 em cada categoria temática pela taxa de crescimento entre os governos FHC e PT

\begin{tabular}{|c|c|c|c|c|}
\hline \multirow{2}{*}{ Categorias temáticas } & \multicolumn{4}{|c|}{ Quantidade de artigos } \\
\cline { 2 - 5 } & $\mathbf{1 9 9 5 - 2 0 0 2}$ & $\mathbf{2 0 0 3 - 2 0 1 0}$ & $\mathbf{2 0 1 1 - 2 0 1 4}$ & $\begin{array}{c}\text { Taxa de } \\
\text { crescimento }\end{array}$ \\
\hline Política Pública & 3 & 21 & 33 & $18,0 \times$ \\
\hline Ação Coletiva & 2 & 7 & 13 & $10,0 \times$ \\
\hline $\begin{array}{c}\text { Concepções sobre temas } \\
\text { políticos e construção de } \\
\text { práticas cotidianas }\end{array}$ & 15 & 59 & 82 & $9,4 \times$ \\
\hline $\begin{array}{c}\text { Modelos teóricos } \\
\text { e dimensão política }\end{array}$ & 7 & 32 & 31 & $9,0 \times$ \\
\hline Estado & 1 & 2 & 4 & $5,0 \times$ \\
\hline Intervenção Política & 2 & 6 & 3 & $4,5 \times$ \\
\hline Total & 30 & 127 & 166 & $9,8 \times$ \\
\hline
\end{tabular}

Ainda que possamos considerar o período de formação das e dos pesquisadores mapeados, bem como o aumento da pressão por produtividade nos últimos anos, esta distribuição númerica dos artigos pode ser pensada também em termos da orientação da política de ciência e tecnologia nos governos PSDB e nos governos petistas.

No caso dos governos FHC, Lima (2011) demonstra que, sob o ideário neoliberal do governo e, portanto, de cortes de gastos sociais e incentivo à iniciativa privada, ano após ano observou-se a queda do número de bolsas de estudo e de verbas para o fomento à pesquisa no país. Em convergência com isso, Pavan Serafim e Peixoto Dagnino (2011) afirmam que o cenário de restrição de financiamento público aliado à reforma gerencial 
do Estado promovida com vigor a partir do primeiro governo FHC limitou a atuação de empresas estatais, institutos públicos de pesquisa e, sobretudo, das universidades públicas na construção de ciência e tecnologia no país.

O paradoxo referente neste contexto de redução de investimentos do Estado, e termos observado um crescimento acentuado no número de programas de pós-graduação, pode ter como um dos importantes elementos explicativos a necessidade de produção de mão-de-obra qualificada (mestres e doutores) para as faculdades privadas (Lima, 2011). $\mathrm{O}$ que pode ser entendido a partir do incentivo do Ministério da Educação nos governos FHC à abertura de novos estabelecimentos de ensino superior na iniciativa privada, sendo que para tal exigia-se um número mínimo de mestres no quadro docente (Lima, 2011).

No período do governo FHC houve um aumento do número de instituições privadas no país em relação às públicas: em 1994, 25,6\% das instituições de ensino superior eram públicas e 74,4 \% privadas; já em 2003, 11,1\% das instituições eram públicas e 88,9\% privadas. A abertura de novos cursos de pós-graduação, contudo, ocorreu, principalmente, em instituições públicas, o que se fez com condições financeiras aquém do mínimo necessário (Lima, 2011).

Nos governos petistas observa-se uma continuidade do aumento no número de PPG, mas agora com um investimento mais significativo no fomento à pesquisa, como pode-se observar a partir do aumento do número de bolsas de doutorado e de mestrado financiadas pelo CNPq e pela CAPES (MEC/CAPES, 2010). Isto converge com o maior número de produção científica nestes governos em relação ao periodo do governo FHC. O eixo estruturante da Política de Ciência e Tecnologia do governo Lula

denominado de Expansão e Consolidação do Sistema Nacional de Ciência, Tecnologia e Inovação - visava aprimorar e consolidar o sistema nacional de CT\&I por meio de ações e programas que promovessem a infra-estrutura, o fomento à pesquisa e à formação de recursos humanos, e que consolidassem e aprimorassem os fundos setoriais, instrumento de financiamento criado no Governo FHC. O foco desse eixo eram as bolsas de estudo e a promoção do desenvolvimento científico e tecnológico brasileiro. (Pavan Serafim \& Peixoto Dagnino, 2011, p. 418)

Ainda que consciôs que não há uma determinação exclusiva das ações destes governos nos temas políticos trabalhados nos artigos, alguns aspectos característicos do contex to histórico e político do governo FHC (PSDB) e dos governos do PT podem ser relacionados ao estudo de determinadas temáticas. Como apresentamos na metodologia, exploramos em relação a este período temporal (1995-2014) a discussão referente à categoria "Políticas Públicas", centrando-nos em artigos referentes a políticas públicas dirigidas à pobreza e à vulnerabilidade social no caso do período dos governos do PT.

\section{Governos FHC: neoliberalismo e política pública}

No período dos governos FHC somente três artigos selecionados focalizam o debate sobre políticas públicas. Dois deles (Bandeira, Gelinas, \& Lesage, 1998; Carvalho \& Yamamoto, 2002) referem-se à discussão sobre política pública de saúde, focalizando dificuldades na implementação das demandas democráticas emergentes neste campo nos anos 1970 e 1980. 
Bandeira, Gelinas e Lesage (1998) aborda problemas na prática tradicional de reintegração de pessoas portadoras de distúrbios psiquiátricos e a constante re-hospitalização destes sujeitos, defendendo a necessidade de construção de alternativas à hospitalização. Discussão possível de ser localizada no debate da reforma psiquiátrica no Brasil, que emergiu no país nos anos 1970 e 1980 com o objetivo de enfrentar as necessidades da saúde da população brasileira e assinalar as atrocidades cometidas pelo modelo manicomial (Aragaki, Spink \& Bernardes, 2012).

Carvalho e Yamamoto (2002) discutem implicações da reforma neoliberal do Estado brasileiro na atuação do psicólogos nos serviços de saúde pública no Brasil. Debate que converge diretamente com o ideário neoliberal defendido pelos governos FHC.

Segundo Lima (2011), embora pautado sob um discurso social-democrata, a primeira e segunda gestões do governo FHC orientaram-se, predominantemente, por pressupostos neoliberais, na conversão das garantias dos direitos sociais em serviços privados regulados pelo mercado e em um programa acirrado de cortes de gastos sociais. Rejeita-se a intervenção do Estado não apenas no controle do mercado, mas também nas políticas sociais, de modo que a privatização dos serviços públicos torna-se estrutural (Lima, 2011). Política que se localiza, portanto, na contramão da proposta de universalização e estatização progressiva do sistema de saúde que orientou a constituição do SUS.

De acordo com Pavan Serafim e Peixoto Dagnino (2011), se a decisão política-ideológica pela orientação neoliberal foi feita já na década de 1980, sendo realizada como saída para a estagnação econômica que acometia o país, a implementação deste modelo intensificou-se a partir de 1995. Segundo os autores, as medidas neoliberais acarretaram num perfil filantrópico para as políticas sociais brasileiras e também acabaram por aniquiliar a possibilidade de um Estado de Bem-Estar Social, que orientou as conquistas sociais da Constituição de 1988. Este quadro acarretou na intensificação do fenômeno da exclusão social e que, em conjunto com transformações nas bases produtivas do capitalismo (globalização, automatização), contribuiu para que trabalhadores, mesmo com emprego formal, fossem coagidos a aceitar a precarização de relações de trabalho diante do risco da perda do emprego (Pavan Serafim \& Peixoto Dagnino, 2011).

O terceiro artigo categorizado em "Políticas Públicas” (Campos \& Alverga, 2001) focaliza o histórico das políticas públicas para criança. Aborda como a crença na ideologia da dignidade do trabalho atua como forma de legitimação do trabalho infantil, inclusive orientando ações de agentes responsáveis pelas políticas públicas voltadas para as crianças. 
Governos PT:

políticas públicas dirigidas à pobreza e à vulnerabilidade social

Cinquenta e quatro artigos foram categorizados em "Políticas Públicas", entre 2003 e 2014, os quais abordam diferentes políticas públicas.

Tabela 3-Quantidade de artigos publicados entre 2003 e 2014 por temáticas referentes à categoria Políticas Públicas

\begin{tabular}{|c|c|c|}
\hline \multirow{2}{*}{ Temáticas referentes à política pública } & \multicolumn{2}{|c|}{ Quantidade de artigos } \\
\cline { 2 - 3 } & $\mathbf{2 0 0 3 - 2 0 1 0}$ & $\mathbf{2 0 1 1 - 2 0 1 4}$ \\
\hline Políticas para criança, adolescente e juventude & 5 artigos & 8 artigos \\
\hline Política de saúde & 5 artigos & 7 artigos \\
\hline Políticas dirigidas à pobreza e à vulnerabilidade social & 3 artigos & 8 artigos \\
\hline Política de Igualdade Racial e Política Indigenista & 2 artigos & 5 artigos \\
\hline Política de Educação & 3 artigos & 2 artigos \\
\hline Política de Direitos sexuais & 1 artigo & 1 artigo \\
\hline Políticas dirigidas à população idosa & 1 artigo & - \\
\hline Política de drogas & - & 1 artigo \\
\hline Política de Defesa do Consumidor & 1 artigo & - \\
\hline Política Ambiental & - & 1 artigo \\
\hline
\end{tabular}

Entre as três políticas públicas mais discutidas no período dos governos PT, duas estavam presentes em artigos selecionados no período dos governos FHC: política pública de saúde e política pública dirigida à criança, ao adolescente e à juventude. Como apresentado na metodologia, discutiremos no período entre 2003 e 2014 os artigos referentes à "Políticas Públicas dirigidas à pobreza e à vulnerabilidade social" (11 artigos).

Neste sentido, cabe-nos ressaltar que a Estratégia Nacional de Ciência, Tecnologia e Inovação proposta pelo governo Lula tinha como objetivo colocar a ciência e a tecnologia a serviço do crescimento, da produção e da distribuição de riqueza, sendo a inclusão social um dos objetivos prioritários desta política cientifica (Pavan Serafim \& Peixoto Dagnino, 2011).

Apesar de similaridades entre os objetivos da política de ciência e tecnologia nos governos FHC e no governo Lula, Pavan Serafim e Peixoto Dagnino (2011) ressaltam que a criação, em 2003, da Secretaria Nacional de Ciência e Tecnologia para Inclusão Social (SECIS) é uma mudança importante na história da política de ciência e tecnologia no Brasil: articula diretamente esta política aos objetivos da inclusão social, enquanto historicamente ela esteve orientada para os interesses de uma burguesia conservadora.

A inserção de novos atores sociais nos processos decisórios (movimentos sociais) e a intensificação de recursos destinados ao problema da exclusão social (como a preocupação com a insegurança alimentar e a geração de trabalho de emprego e renda), ainda que não romperam totalmente com a lógica de governos anteriores, enfatizou "a valorização da ciência e da tecnologia como vetores da inclusão social” (Pavan Serafim \& Peixoto Dagnino, 201 1, p. 424).

É importante considerar que se, por um lado, é possível afirmar que os governos do PT afirmaram a centralidade do enfrentamento à exclusão social e da expansão de direitos 
democráticos, por outro lado, isso não se fez sem ambiguidades. Esta expansão ocorreu de maneira concomitante à incorporação por estes governos de reivindicações contrárias a demandas de grupos sociais historicamente aliados ao projeto político do PT de democratização da sociedade brasileira (Costa \& Prado, 2017; Sandoval, 2005).

Neste contexto, observa-se nos artigos mapeados problematizações referentes às políticas públicas que se dirigiram à pobreza e à vulnerabilidade social, permitindo-nos considerar a importância da atuação crítica da universidade e da pesquisa na produção de conhecimento.

Os artigos de Scisleski e Maraschin (2008), de Scisleski, Reis, Hadler, Weigert e Guareschi (2012), de Curado e Spink (2014) e de Muniz, Lima, Miranda e França (2014), trazem como preocupação a relação entre as práticas construídas nas políticas públicas e os modos de subjetivação de indivíduos em condição de pobreza e de vulnerabilidade submetidos a estas políticas.

Scisleski \& Maraschin (2008) analisam os efeitos da internação psiquiátrica compulsória, destinada a adolescentes usuários de drogas que vivem em situação de marginalidade social, nas políticas públicas e nos processos de subjetivação destes adolescentes. Concebe-se que a ordem judicial nos encaminhamentos pode funcionar tanto como uma forma de punição aos adolescentes quanto como um meio de acesso aos serviços de saúde.

Scisleski e colaboradores (2012), atentando-se para as práticas psicológicas nas políticas públicas de saúde, assistência social e justiça, concebem que, ao contrário de proporcionarem proteção social aos jovens vítimas de violação de direitos, têm produzido ações normalizadoras e punitivas na vida destes jovens. Afirmam que entender os discursos acerca dos jovens em conflito com a lei e as práticas as quais são submetidos é um caminho potente para a produção de deslocamentos no lugar da psicologia nas políticas públicas.

Curado e Spink (2014), ao buscarem compreender a política pública de enfrentamento à pobreza através do programa Bolsa Família, discutem a construção de três versões de pobreza distintas em ações deste programa. Diante disso, concebem que o reconhecimento destas versões como relativas ao caráter múltiplo e complexo da pobreza pode contribuir para desestabilizar noções tradicionais de pobre e de pobreza.

Muniz, Lima, Miranda e França (2014) investigam a história do pensamento assistencialista acerca do "adolescente pobre" no contex to brasileiro e o modo como este grupo passou a ser alvo de um conjunto de práticas de Estado e de políticas públicas que produziram uma determinada identidade do que é ser "adolescente pobre".

Outros cinco artigos enfatizam o impacto do neoliberalismo e do sistema capitalista na construção das políticas públicas e nas práticas dos psicólogos nestas políticas. Neste sentido, o artigo de Luz e Vecchia (2012) permite-nos articular os anos de governo FHC e de governos PT, uma vez que os autores, ao partirem da compreensão de que medidas econômicas neoliberais impactaram mundialmente a condução das políticas sociais durante a década de 1990 e que isso também se fez notar, em nosso país, na atuação do psicólogo, discutem se o neoliberalismo continuava vigente naquele contexto (início do governo Dilma). De acordo com os autores, "Um dos maiores desafios do século XXI consistirá no enfrentamento das históricas desigualdades por meio de políticas sociais que não sejam tão somente um paliativo à pobreza" (p. 311 ).

Os artigos de Yamamoto e Oliveira (2010), Oliveira e Amorim (2012), Seixas e Yamamoto (2012) enfocam a inserção dos psicólogos no campo do bem-estar social nas últimas décadas, refletindo sobre a precariedade das condições estruturais desta inserção, 
bem como sobre as práticas produzidas pelos psicólogos. Em um destes artigos afirma-se que "mais que intervir no sofrimento psicológico, cabe ao psicólogo manejar situações cujos determinantes repousam nas condições estruturais da sociedade burguesa, especialmente aqueles resultantes da contradição fundamental entre capital e trabalho" (Oliveira \& Amorim, 2012, p. 559).

Monteiro, Coimbra e Mendonça Filho (2006) colocam em questão a própria possibilidade de se construir políticas públicas efetivas de proteção social a partir da via Estatal no sistema capitalista. Os autores ressaltam o cenário de apartheid social produzido pelo Estado capitalista, onde, apesar da precarização do mercado de trabalho, difunde-se cada vez mais a subjetividade do trabalho formal como a verdadeira natureza do homem, de modo que se concebe como "cidadão humano" apenas aquele que se vincula, rápida e prontamente, à lógica capitalista. Eles propõem a necessidade de se repensar a relação entre Estado e políticas públicas, no sentido de se compreender que práticas públicas não precisam estar necessariamente vinculadas ao Estado. Neste sentido, defendem a construção destas práticas a partir da experiência concreta dos homens, em suas lutas, e não a partir do homem idealizado, de direitos idealizados.

Também no interior do debate sobre a necessidade de repensar a construção de políticas públicas, Perrone e Santos (2013), ao abordarem a política pública de assistência social, defendem a necessidade de se devolver ao usuário desta política uma experiência de singularização. Para tanto, apontam o campo dos Direitos Humanos como aquele que pode estabelecer fronteiras em relação ao assistencialismo e à psicologização que historicamente permeou a política pública de assistência social no Brasil, e, assim, que possibilite a afirmação desta política como uma política efetiva de proteção social.

No último dos 11 artigos que focalizam o debate sobre políticas públicas dirigidas à pobreza e à vulnerabilidade social, Reis, Guareschi, Huning e Azambuja (2014) discutem a produção de conhecimento em Psicologia Social no Brasil sobre as temáticas de risco e vulnerabilidade social, tendo como objetivo compreender como estes saberes têm sustentado as práticas em políticas públicas.

\section{Considerações finais}

A reflexão crítica sobre a sociedade durante o regime civil-militar brasileiro, mesmo na existência de fomento à pesquisa e à pós-graduação, foi inibida, devido a censura política à produção científica, motivo importante para a escassez de debates científicos sobre temas políticos neste período. Monteiro (1995), ao constatar uma ausência de análises de temas políticos na América Latina entre 1956-1986, aponta ser inevitável a associação entre regimes democráticos e a produção destas análises, uma vez que, diante dos governos totalitários presentes no continente latino-americano naquele contexto, alguns temas políticos eram inexistentes (comportamento eleitoral, percepção de partidos políticos, por exemplo) e outros impossíveis de serem investigados (socialização política, ideologias políticas, estereótipos, por exemplo) sem o risco do/a pesquisador/a ser perseguido e violentado.

O quadro contextual apresentado, contudo, permite-nos dizer também que a existência de um regime democrático, que permite a investigação de temas políticos, quando caracterizado pela precarização das universidades públicas, como ocorreu nos governos FHC, não necessariamente contribui para a expansão da produção científica, pois diminui 
as condições de possibilidade de desenvolvimento de pesquisa nestas universidades, nas quais ensino e pesquisa devem ser pilares complementares.

Nesta medida, é interessante perceber o aumento quantitativo das produções sobre temas políticos mapeadas no contexto de regime democrático dos governos Lula e Dilma. Governos que, ainda que de maneira ambígua, contribuíram para a expansão da universidade pública e se orientaram para o enfrentamento a relações de desigualdade, inclusive, no que tange ao fomento à pesquisa na universidade.

$\mathrm{Na}$ atualidade, ano 2017, o país encontra-se em um momento histórico no qual - após a condução de um impeachment questionável da presidenta da República, que colocou em questão a própria instituição da democracia - a presidência da República foi ocupada por um governo que, entre outras ações, tem aumentado a contenção de verbas para as universidades públicas, iniciada no segundo governo Dilma. Situação que, em conjunto com o fortalecimento de pautas conservadoras no país, que atingem diretamente as possibilidades de reflexão crítica sobre a sociedade ("Escola sem Partido", "Ideologia de Gênero", por exemplo), novamente traz riscos para o fomento à pesquisa e à pós-graduação no Brasil e para a investigação de temas políticos, sendo importante a realização de futuras investigações sobre o impacto na produção científica brasileira desta reordenação do contexto político do país em relação aos 13 anos de governos do PT.

Quanto ao conteúdo dos artigos, é interessante apontar novamente o crescimento de investigações referentes à política pública nas produções selecionadas, indicando para uma preocupação da Psicologia Social no Brasil em refletir sobre a implementação e a efetivação pelo Estado de direitos sociais conquistados historicamente pela população brasileira. Aspecto importante de ser sinalizado na formação dos psicólogos sociais, de modo a continuarmos a reafirmar, mesmo que mais de três décadas depois da emergência da "crise da psicologia social”, abordagens psicossociológicas que se contrapõem a análises individualistas das condições sociais e políticas que, ao invés de contribuírem para a expansão da democracia, reforçam a reprodução de desigualdades.

\section{Referências}

Aragaki, S. S., Spink, M. J., \& Bernardes, J. S. (2012). La Psicología de la Salud en Brasil: transformaciones de las prácticas psicológicas en el contexto de las políticas públicas en el área de la salud. Pensamiento Psicológico, $10(2), 65-82$.

Bandeira, M., Gelinas, D., \& Lesage, A. (1998). Desistitucionalizaçäo: o programa de acompanhamento intensivo na comunidade. Jornal Brasileiro de Psiquiatria, 47(12), 627-640.

Bomeny, H. (2014). Um personagem e suas histórias. Ciência e Cultura, 66(4), 38-43.

Bosi, E. (1992). Entre a opinião e o estereótipo. Novos Estudos, CEBRAP, 32, 111-118.

MEC/CAPES (2010). Plano Nacional de Pós-graduação-PNPG 201 1-2020 / CAPES. Brasília, DF: Autores. Recuperado de link que leve ao plano....

Camino, L. \& Costa, J. B. (1994). A participação política do adolescente: indicação de uma abordagem psico-social a partir da noção de identidade. Temas em Psicologia, 2(1), 1-16.

Campos, H. R. \& Alverga, A. R. (2001). Trabalho infantil e ideologia: contribuição ao estudo da crença indiscriminada na dignidade do trabalho. Estudos de Psicologia, (Natal), 6(2), 227-233. 
Carvalho, D. B. \& Yamamoto, O. H. (2002). Psicologia e políticas públicas de saúde: anotações para uma análise da experiência brasileira. Psicologia para América Latina, 1, 1-8.

Costa, F. A. (2014). A dimensão do político na Psicologia Social no Brasil (1986-2011): uma análise da produção científica a partir da Teoria Democrática Radical e Plural. Tese de Doutorado, Programa de Pós-graduação em Psicologia, Universidade Federal de Minas Gerais, Belo Horizonte, $\mathrm{MG}$.

Costa, F. A. \& Prado, M. A. M. (2017). Artimanhas da hegemonia: obstáculos à radicalização da democracia no Brasil. Psicologia E Sociedade, 29. https://doi.org/10.1590/ $1807-0310 / 2017 \mathrm{v} 29152680$

Costa, J. B., Torres, A. R. R., Burity, M. H. L, \& Camino, L. (1994). Universidade: espaço institucional para o desenvolvimento político. Temas em Psicologia, 2(1), 17-35.

Coutinho, M. L. R. (1990). Em que espelho ficou perdida a minha face? A identidade feminina como discurso ideológico. Psicologia E Sociedade, 5(8), 34-48.

Curado, J. C. \& Spink, M. J. (2014). Multiplicidades da pobreza nas políticas públicas contemporâneas: contribuições do construcionismo social e da Teoria-Ator-Rede (TAR). Diálogo, 27, 09-23.

Ferreira, M. C. (1993). Estereótipos de gênero: estrutura interna e conteúdo. Arquivos Brasileiros de Psicologia, 45(1-2), 42-54.

Guedes, M. C. (2007). A viagem histórica pela América Latina. Psicologia Ẽ Sociedade, 19(n. spe.2), $39-45$

Laclau, E. \& Mouffe, C. (1985). Hegemony and Socialist Strategy. Towards a radical democratic politics. London: Verso.

Lane, S. T. M. \& Codo, W. (1987). Psicologia social: o homem em movimento. São Paulo: Editora Brasiliense.

Lima, P. G. (2011). Política Científica E Tecnológica no Brasil no governo Fernando Henrique Cardoso (1995-1998). Dourados/MS: Editora UFGD.

Luz, L. F. L. \& Vecchia, M. D. (2012). Pós-neoliberalismo, políticas sociais e práticas psicossociais na atuação do psicólogo. Pesquisas e Práticas Psicossociais, 7(2), 311-322.

Mello, S. L. (1992). Classes populares, família e preconceito. Psicologia, USP, 3(1-2), 123-130.

Mello, S. L. (1994). Famílias das classes populares: tradiçäo e mudança. Revista Brasileira de Crescimento e Desenvolvimento Humano, 4(1), 21-27.

Montero, M. (1995). La psicología política en America Latina: una revisión bibliográfica: 19561986. In J. Elster (Org.), Psicologia política (pp. 15-47). Barcelona, ESP: Gedisa Editorial.

Monteiro, A., Coimbra, C., \& Mendonça, M. (2006). Estado democrático de direito e políticas públicas: estatal é necessariamente público? Psicologia E Sociedade, 18(2), 7-12

Moreira, I. C. (2014). A ciência, a ditadura e os físicos. Ciência e Cultura, 66(4), 48-53.

Motta, R. P. S. (2014). A ditadura nas universidades: repressão, modernização e acomodação. Ciência e Cultura, 66(4), 21-26.

Muniz, J. S. M., Lima, A. F., Miranda, L. L., \& França, L. C. (2014). Vigiar e assistir: reflexões sobre o direito à assistência da 'adolescência pobre'. Psicologia em Estudo, 19(2), 32 1-331. 
Oliveira, I. F. \& Amorim, K. M. O. (2012). Psicologia e política social: O trato da pobreza como “sujeito psicológico”. Psicologia Argumento, 30(70), 559-566.

Pavan Serafim, M. \& Peixoto Dagnino, R. (2011). A política científica e tecnológica e as demandas da inclusão social no governo Lula (2003-2006). Organizações E̊ Sociedade, 18(58), 403-427.

Perrone, C. \& Santos, A. (2013). Direitos Humanos: um desafio para nova politica de assistência social brasileira. Revista Sociais e Humanas, 26(1), 103-108.

Prado, M. A. M. (2001). Psicologia política e ação coletiva: notas e reflexões acerca da compreensão do processo de formação identitária do “nós”. Revista Psicologia Política, 1(1), 149-172.

Reis, C., Guareschi, N. M. F., Hünning, S. M., \& Azambuja, M. A. (2014). A produção do conhecimento sobre risco e vulnerabilidade social como sustentação das práticas em políticas públicas. Estudos de Psicologia (Campinas), 31(4), 583-593.

Sandoval, S. (1989). Considerações sobre aspectos micro-sociais na análise dos movimentos sociais. Psicologia E Sociedade, 4(7), 61-72.

Sandoval, S. (1991). Los mecanismos de discriminación racial en el Mercado de trabajo: el caso del Brasil urbano. Estudios Sociológicos, 9(25), 35-60.

Sandoval, S. (2002). O que há de novo na psicologia social latino-americana. In R. H. Campos \& P. Guareschi (Orgs.), Paradigmas em psicologia social: a perspectiva latino-americana (pp. 101109). Petrópolis, RJ: Vozes.

Sandoval, S. (2005). The Lula Government: the challenges of the PT in power and contradictions of power. Journal of Iberian and Latin American Studies, 11(2), 79-91.

Sawaia, B. B. (1989). Pesquisa açäo participante: a práxis científica com vocaçäo política. Enfoque, $17(3), 60-63$.

Scisleski, A. C. C. \& Maraschin, C. (2008). Internação psiquiátrica e ordem judicial: saberes e poderes sobre adolescentes usuários de drogas ilícitas. Psicologia em Estudo, 13(3), 457-465.

Scisleski, A. C. C., Reis, C., Hadler, O., Weigert, M. A. B., \& Guareschi, N. M. F. (2012). Juventude e pobreza: a construção de sujeitos potencialmente perigosos. Arquivos Brasileiros de Psicologia, 64(3), 19-34.

Seixas, P. S. \& Yamamoto, O. H. (2012). A inserção e a atuação profissional do psicólogo no campo das políticas sociais no Rio Grande do Norte. Psicologia Argumento, 30(70), 477-489.

Stralen, C. J. V. (1983). Movimentos Sociais Urbanos e a Democratização dos Serviços de Saúde. Revista Brasileira de Administração Pública, 17(3), 38-60.

Stralen, C. J. V. (1984). A Democratização dos Serviços de Saúde: O programa de trabalho do Centro Metropolitano de Saúde. Saúde em Debate, 15, 49-50.

Stralen, C. J. V. (1989). A luta do movimento sindical dos trabalhadores rurais pela equiparaçào da assistência médica urbana e rural. Saúde em Debate , 24, 28-36.

Tourinho, E. Z. \& Bastos, A. V. B. (2010). Desafios da Pós-Graduação em Psicologia no Brasil. Psicologia: Reflexão e Crítica, 23(1), 35-46.

Yamamoto, O. H. \& Oliveira, I. F. (2010). Política Social e Psicologia: uma trajetória de 25 anos. Psicologia: Teoria e Pesquisa, 26(n.spe), 9-24.

Yamamoto, Tourinho, Bastos \& Menandro (2012). Produção científica e 'produtivismo': há alguma luz no fim do tunel? $R B P G, 9(18), 727-750$. 
FREDERICO ALVES COSTA

https://orcid.org/O000-0001-9150-8675

Doutor em Psicologia pela Universidade Federal de Minas Gerais (Bolsista CAPES). Doutoramento-Sanduíche no Instituto de Ciências Sociais da Universidade de Lisboa (CAPES/PDSE). Mestre em Psicologia pela Universidade Federal de Minas Gerais (Bolsista CAPES). Realizou Estágio Pós-Doutoral (PNPD/CAPES) no Programa de Pós-graduação em Psicologia da Universidade Federal de Alagoas (UFAL). Professor Adjunto no Instituto de Psicologia da UFAL e Professor Permanente no Programa de Pós-graduação em Psicologia da UFAL.

Endereço: Av. Lourival de Melo Mota -Tabuleiro do Martins - Maceió-AL CEP: 57072-970

E-mail: fredericoalvescosta@gmail.com

\begin{tabular}{|l|l|}
\hline \multirow{2}{*}{ Histórico } & $\begin{array}{l}\text { Submissão: 29/10/2017 } \\
\text { Revisão: 16/11/2018 } \\
\end{array}$ \\
\hline Financiamento $13 / 11 / 2019$ \\
\hline Não houve. \\
\hline
\end{tabular}

